\title{
Aberrant expression and high-frequency mutations of SHARPIN in nonmelanoma skin cancer
}

\author{
YAN ZHENG, YAO YANG, JIAMAN WANG and YANHUA LIANG \\ Department of Dermatology, Shenzhen Hospital, Southern Medical University, \\ Shenzhen, Guangdong 518100, P.R. China
}

Received March 20, 2018; Accepted February 5, 2019

DOI: $10.3892 /$ etm.2019.7261

\begin{abstract}
Squamous cell carcinoma (SCC) and basal cell carcinoma (BCC) have exhibited a marked increase in incidence in previous decades and are the most common malignancies in Caucasian populations. Src homology 3 and multiple ankyrin repeat domains protein-associated $\mathrm{RH}$ domain-interacting protein (SHARPIN) has been identified as a commonly overexpressed proto-oncogene in several types of visceral cancer. However, to the best of our knowledge, the functions of SHARPIN in nonmelanoma skin cancer (NMSC) have not been described. The present study aimed to investigate the expression of SHARPIN protein and SHARPIN mutations in NMSC. A total of 85 BCC, 77 SCC and 21 keratoacanthoma (KA) formalin-fixed paraffin-embedded (FFPE) samples were collected. SHARPIN expression was detected using immunohistochemistry. DNA was extracted from the FFPE samples, and the sequences of SHARPIN were analyzed using polymerase chain reaction. In addition, high and moderate expression levels of SHARPIN were observed in normal skin tissues and KA samples. However, the expression of SHARPIN was absent in cancer nests and was significantly low in precancerous NMSC lesions. The total mutation frequency of SHARPIN was $21.8 \%$ in BCC and $17.0 \%$ in SCC. These data indicate that SHARPIN may serve a tumor-suppressing role and be a promising diagnostic, prognostic and therapeutic biomarker in NMSC.
\end{abstract}

\section{Introduction}

The incidence of nonmelanoma skin cancer (NMSC), which includes squamous cell carcinoma (SCC) and basal cell

Correspondence to: Dr Yanhua Liang, Department of Dermatology, Shenzhen Hospital, Southern Medical University, 1333 Xinhu Road, Shenzhen, Guangdong 518100, P.R. China E-mail: liangdoctor@163.com

Key words: Src homology 3 and multiple ankyrin repeat domains protein-associated RH domain-interacting protein, mutation, basal cell carcinoma, squamous cell carcinoma, formalin-fixed paraffin-embedded block carcinoma (BCC), has exhibited a marked increase in the previous decade and at present is the most common malignancy in Caucasian populations (1). NMSC is associated with a low rate of mortality but a high rate of disfigurement in cases where skin lesions are located on the head and neck. In addition, SCC occurs less frequently compared with BCC but is generally more aggressive. Sunlight (2), viral infection (3), diet (4), immunosuppression in organ transplant recipients (5) and induction of spontaneous genetic mutations (6) have been regarded as causes for NMSC. Tumors are markedly associated with chronic ultraviolet (UV) radiation exposure and occur primarily on sun-exposed areas of the body (7). Early detection and surgical removal may prevent the majority of complications. However, skin cancer has a high rate of recurrence and occasionally tumors progress to advanced stages that are difficult to treat with present therapeutic modalities; additionally, advanced-stage tumors become associated with high morbidity and decreased survival rates (8). At present, treatment options have remained limited for locally advanced or metastatic NMSC. Therefore, an in-depth understanding of the molecular basis of skin tumorigenesis is necessary in order to develop novel and specific diagnostic biomarkers and efficient therapies.

Src homology 3 and multiple ankyrin repeat domains protein (SHANK)-associated RH domain-interacting protein (SHARPIN) is a 387-amino acid protein that was originally identified as a SHANK-binding protein, which is enriched in the postsynaptic density of excitatory neurotransmitters (9). In addition, SHARPIN has been detected in cancer in the brain, spleen, lungs and other organs. Seymour et al (10) have identified SHARPIN as a gene mutated in chronic proliferative dermatitis $(c p d m)$ mice $\left(\right.$ Sharpin $\left.^{c p d m / c p d m}\right)$ which spontaneously causes chronic inflammation, primarily in the skin, but also in other tissues including the gut, lung, liver and esophagus. SHARPIN has been previously identified as a common component of the linear ubiquitin chain assembly complex (LUBAC) which also contains E3 ubiquitin protein ligase ring finger protein 31 and RanBP-type and C3HC4-type zinc finger-containing protein 1 (HOIL-1L) (11). The C-terminal portion of SHARPIN consists of a ubiquitin-like (UBL) domain followed by an Npl4-zinc finger (NZF) domain and is important for the formation of a complex with the LUBAC component, haem-oxidized iron-regulatory protein 2 ubiquitin ligase-1 interacting protein and ubiquitin (9). 
LUBAC is an important component of the nuclear factor kappa-light-chain-enhancer of activated $B$ cells $(N F-\kappa B)$ signaling pathway, which is a critical regulator of inflammation, immune response and lymphoid tissue development (12). $\mathrm{NF}-\kappa \mathrm{B}$ signaling is generally classified into canonical and non-canonical pathways. The canonical pathway, primarily triggered by tumor necrosis factor (TNF), lipopolysaccharides, and $\mathrm{T}$ and $\mathrm{B}$ cell receptors, occurs in the majority of cells as the principal NF- $\kappa \mathrm{B}$ pathway. Upon stimulation, the downstream kinase inhibitor of $\kappa \mathrm{B}(\mathrm{I} \kappa \mathrm{B})$ kinase (IKK) complex, composed of two catalytic subunits (IKK $\alpha$ and IKK $\beta$ ) and one regulatory subunit $[N F-\kappa B$ essential modulator (NEMO)], is activated, allowing the phosphorylation of the $\mathrm{I} \kappa \mathrm{B} \alpha$ inhibitory protein. A linear form of polyubiquitin chains was previously identified in the $N F-\kappa B$ signaling pathway following TNF stimulation (13). The generation of linear ubiquitin polymers is catalyzed by LUBAC. Previous evidence indicates that LUBAC is recruited to TNF receptor complexes upon TNF induction, and then conjugates linear ubiquitin chains to the regulatory subunit NEMO of the IKK complex (14). This activates the kinase activity of IKK and ubiquitin-dependent degradation of phosphorylated $\mathrm{I} \kappa \mathrm{B} \alpha$, therefore enabling the nuclear translocation of $\mathrm{NF}-\kappa \mathrm{B}$ dimers and downstream gene expression (15). SHARPIN contains a $\mathrm{PH}$ (pleckstrin homology) domain at the N-terminus, which serves as a dimerization domain and may serve a role in other physiological functions of SHARPIN, including its tumor-associated role and its ability to inhibit $\beta 1$-integrin activation (16). Furthermore, SHARPIN has been identified as a commonly overexpressed proto-oncogene and functionally serves tumor-associated roles during cancer progression according to previous studies (17-23). However, data regarding the function of SHARPIN in the pathogenesis and development of NMSC is lacking. These background data prompted the present study to investigate the expression and mutations of SHARPIN in skin tumors and identify a promising prognostic biomarker and therapeutic target for NMSC. Immunohistochemistry was utilized in the current study to assess SHARPIN expression in NMSCs and polymerase chain reaction (PCR) was used to detect mutations of SHARPIN in NMSCs. It was revealed that the expression of SHARPIN was absent in cancer nests and was significantly low in precancerous NMSC lesions. The total mutation frequency of SHARPIN was $21.8 \%$ in BCC and $17.0 \%$ in SCC.

\section{Materials and methods}

Literature retrieval. To acquire all literature regarding SHARPIN and NMSCs, PubMed (https://www.ncbi.nlm.nih. gov/pubmed) was searched using the following search string to identify relevant papers: (NMSC) OR non-melanoma skin cancer AND SHARPIN. No restrictions on publication date or language were imposed during the search strategy. No articles were identified.

Specimen selection. Anonymized control DNA samples from blood specimens of 100 normal individuals and skin tissues from 12 healthy volunteers who received cosmetic surgeries were obtained according to a protocol approved by the Southern Medical University Shenzhen Hospital Subject Review Board.
All 100 normal individuals and 12 healthy volunteers did not have skin diseases. Formalin-fixed paraffin-embedded (FFPE) samples were retrieved from the Department of Dermatology of Shenzhen Hospital in Southern Medical University (Shenzhen, China). All samples from January 2012 to June 2017 were biopsied. All samples were fixed for $24 \mathrm{~h}$ in $10 \%$ formalin solution at room temperature. The thickness of the sections was $4 \mu \mathrm{m}$. A total of $85 \mathrm{BCC}, 77 \mathrm{SCC}$ and 21 keratoacanthoma (KA) FFPE samples were collected. The diagnoses of the samples were confirmed by pathologists from the Department of Dermatology of Shenzhen Hospital in Southern Medical University. Informed consent was obtained from all patients.

DNA extraction and mutation sequencing. DNA was extracted from the blood using the phenol-chloroform method (24). The FFPE genomic DNA was extracted using a QIAamp DNA FFPE Tissue kit (Qiagen GmbH, Hilden, Germany). To detect hotspot mutations, 8 exons and exon-intron adjacent sequences of the SHARPIN gene were amplified using PCR. In the DNA from the tumor samples, each amplification reaction was performed under standard conditions in a $20 \mu \mathrm{l}$ PCR mixture containing 70-150 ng template DNA, 10 pmol primers, and $10 \mu 12 \mathrm{X}$ Taq Master Mix (Dye Plus) (Vazyme, Piscataway, NJ, USA). The GC percentage of Exon 1 was relatively high; therefore, the 2X Taq Master Mix (Dye Plus) was replaced by 2X Phanta Max Master Mix (Vazyme) in the amplification of Exon 1. The 8 primer pairs that were used are listed in Table I. Exon 3 was amplified by PCR. The thermocycler conditions for the standard and nested PCR protocols are listed in Table II. PCR products were purified using QIAquick reagent (Qiagen $\mathrm{GmbH}$ ) and directly sequenced based on the Big Dye Terminator sequencing chemistry (Applied Biosystems; Thermo Fisher Scientific, Inc., Waltham, MA USA) in an ABI3130 automated sequencer (Applied Biosystems; Thermo Fisher Scientific, Inc.). All mutations were confirmed through repeated bidirectional sequencing on the $\mathrm{ABI}$ sequencer. Gene sequences were blasted using DNASTAR Lasergene 7.1 (DNASTAR Inc., Madison, WI, USA).

Immunohistochemistry. FFPE sections were deparaffinized in xylene at room temperature and rehydrated in 100, 95, 90, 80 and $70 \%$ alcohol solutions prepared with absolute ethyl alcohol and distilled water. For antigen retrieval, sections were heated in citrate buffer $(\mathrm{pH} 6.0)$ for $15 \mathrm{~min}$ at $100^{\circ} \mathrm{C}$ in a microwave oven and naturally cooled to room temperature. Subsequently, the samples were blocked with a mixture of methanol and $0.75 \%$ hydrogen peroxide for $20 \mathrm{~min}$ at room temperature. Following washing with PBS, samples were incubated with SHARPIN antibody (cat. no., sc-98127; Santa Cruz Biotechnology, Inc., Dallas, TX, USA; dilution, 1:100) at $4^{\circ} \mathrm{C}$ overnight. Subsequent to incubation, slides were washed three times with PBS. The slides were then processed using a 2-step Plus ${ }^{\circledR}$ Poly-horseradish peroxidase Anti-Mouse/Rabbit IgG Detection System (cat. no., PV-9000; ZSGB-BIO; OriGene Technologies, Inc., Beijing, China) and were developed with a DAB Detection kit (Enhanced Polymer; cat. no., PV-9000-D; ZSGB-BIO; OriGene Technologies, Inc.) for $3 \mathrm{~min}$ at room temperature. SHARPIN immunohistochemical staining was expected to be localized to the cytoplasm. 
Table I. Primers used in the screening of Src homology 3 and multiple ankyrin repeat domains protein-associated RH domain-interacting protein gene mutations.

\begin{tabular}{lll}
\hline Exon & \multicolumn{1}{c}{ Forward primer (5'-3') } & \multicolumn{1}{c}{ Reverse primer (5'-3') } \\
\hline 1 & CAGGTTCGCGGCCCGTGTTT & AAGAGGACTGACCGCGCGCC \\
2 & ATTTCTTTGCTCCTCGTGCG & CTTCCCAGACATCCAGCAGT \\
3 & CAGCACAGCACACCCATATC & GGGACTATCTGCTATCCCCG \\
4 & AGCAGATAGTCCCCAGTGGT & GTGGGTTCAGGGATGGATGG \\
5 & CATCAGGTGAGGCCTGGG & CCGAGCTCTGAGAACACCTG \\
6 & ATCACCTGCCCTGATGCTC & GTGGAGCTCAGGACTGTGG \\
8 & CACAGTCCTGAGCTCCACC & GTTGCTTCCCTGCTCTTTCC \\
\hline
\end{tabular}

Table II. PCR amplification thermocycler conditions of Src homology 3 and multiple ankyrin repeat domains protein-associated RH domain-interacting protein gene.

\begin{tabular}{|c|c|c|c|c|c|}
\hline \multicolumn{3}{|c|}{ Touchdown PCR } & \multicolumn{3}{|c|}{ Ordinary PCR } \\
\hline Steps & Temperature, ${ }^{\circ} \mathrm{C}$ & Duration & Steps & Temperature, ${ }^{\circ} \mathrm{C}$ & Duration \\
\hline 1 & 94 & $5 \min$ & 1 & 94 & $5 \mathrm{~min}$ \\
\hline 2 & 94 & $30 \mathrm{sec}$ & 2 & 94 & $30 \mathrm{sec}$ \\
\hline 3 & $63, \mathrm{EX}^{\mathrm{a}}-0.5$ & $30 \mathrm{sec}$ & 3 & $60 / 56 / 57^{b}$ & $30 \mathrm{sec}$ \\
\hline 4 & 72 & $20 \mathrm{sec}$ & 4 & 72 & $20 \mathrm{sec}$ \\
\hline 5 & Back to step 2 & 16 times & 5 & Back to step 2 & 35 times \\
\hline 6 & 94 & $30 \mathrm{sec}$ & 6 & 72 & $7 \mathrm{~min}$ \\
\hline 7 & 54 & $30 \mathrm{sec}$ & 7 & 4 & Until use \\
\hline 8 & 72 & $20 \mathrm{sec}$ & - & - & - \\
\hline 9 & Back to step 5 & 20 times & - & - & - \\
\hline 10 & 72 & $7 \mathrm{~min}$ & - & - & - \\
\hline 11 & 4 & Until use & - & - & - \\
\hline
\end{tabular}

PCR, polymerase chain reaction; E, exon. E3 was amplified by Touchdown PCR. E1, E2, E4, E5, E6, E7 and E8 were amplified by ordinary PCR. ${ }^{\mathrm{a}} \mathrm{EX}$ indicates that the annealing temperature decreased by $0.5^{\circ} \mathrm{C}$ per cycle. ${ }^{\mathrm{b}}$ Annealing temperature of $\mathrm{E} 1$ was $60^{\circ} \mathrm{C}$, annealing temperature of $\mathrm{E} 2, \mathrm{E} 4, \mathrm{E} 5$, and $\mathrm{E} 8$ was $56^{\circ} \mathrm{C}$ and annealing temperature of $\mathrm{E} 6$ and $\mathrm{E} 7$ was $57^{\circ} \mathrm{C}$.

Histologic scoring and analysis. Samples were evaluated using a standard light microscopic technique (magnification, x200) as performed by two pathologists (Shenzhen Hospital in Southern Medical University). Staining for the SHARPIN protein was evaluated in the tumors and in the normal skin tissues, which were invariably SHARPIN-positive and served as positive controls. Each tumor sample was scored by the cross-product ( $\mathrm{H}$ score) of the percentage of tumor cell staining at each of the 3 staining intensities. Degrees of staining were divided into four levels: None, 0; weak, 1; moderate, 2; and strong, 3. For example, a particular tumor may have $30 \%$ cell staining at intensity $=1$ and $70 \%$ of cell staining at intensity $=3$, for a combined $\mathrm{H}$ score of 240 $[(30 \times 1)+(70 \times 3)=240]$ out of a maximum of 300. This system was performed as described previously by Bollag et al (25). Concordance was observed between the scores given by the two pathologists $(81 \%$ of the scores were in agreement within a 40-point range). Cases with discrepancies of $<50$ points were recorded and reconciled on a two-headed microscope. Final $\mathrm{H}$ scores for each case were averaged by each pathologist. The expression scale of SHARPIN was graded by $\mathrm{H}$ score as follows: Low, H score 1-100; moderate, $\mathrm{H}$ score 101-200; and high, H score 201-300.

Statistical analysis. Statistical analysis was performed using SPSS 13.0 (SPSS, Inc., Chicago, IL, USA). Data were presented as the mean \pm standard deviation. Differences in SHARPIN expression levels between normal skin and SCC, BCC and KA samples were analyzed using one-way analysis of variance and Tamhane's T2 post hoc test. The Broder grading system of SCC is commonly utilized to assess prognosis. It divides SCC into four categories based on histological grade. Grade I is composed of well-differentiated tumors, in which $75-100 \%$ of squamous cells are differentiated. Grade II is composed of moderately differentiated tumors in which $50-75 \%$ of squamous cells are differentiated. Grade III is composed of 

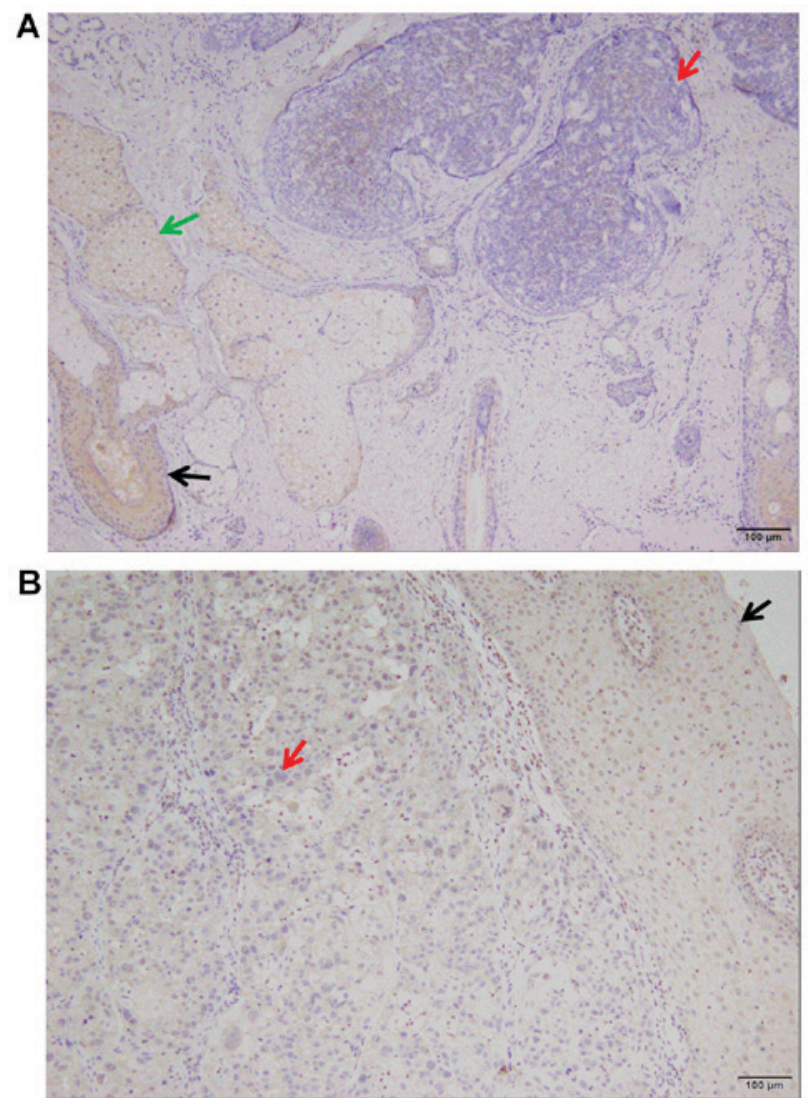

Figure 1. Expression of SHARPIN in nonmelanoma skin cancer. (A) The expression of SHARPIN in BCC at magnification, $\mathrm{x} 100$. The red arrow indicates BCC cells. The black arrow indicates sebaceous glands. (B) The expression of SHARPIN in SCC at magnification, $x 100$. The red arrow indicates SCC cells. The black arrow indicates epithelia. SHARPIN, Src homology 3 and multiple ankyrin repeat domains protein-associated $\mathrm{RH}$ domain-interacting protein; BCC, basal cell carcinoma; SCC, squamous cell carcinoma.

poorly differentiated tumors in which only $25-50 \%$ of cells are differentiated. Grade IV is an anaplastic tumor in which $0-25 \%$ of cells are differentiated (26). Main histologic variants of BCC include nodular type, adenoidal type, superficial type and sclerosing type (27). Associations between SHARPIN expression levels and aforementioned clinicopathological parameters were analyzed using the $\chi^{2}$ test for categorical variables. $\mathrm{P}<0.05$ was considered to indicate a statistically significant difference.

\section{Results}

SHARPIN is aberrantly decreased in human NMSC. The SHARPIN protein was absent in the tumor nests and significantly decreased in precancerous lesions of SCC and BCC (Fig. 1) when compared to normal epithelium (Fig. 2). In addition, SHARPIN was moderately to highly expressed in KA samples (Fig. 3).

In BCC, SHARPIN expression was low in 63 cases $(74.5 \%)$ and moderate in 22 cases (25.5\%). In SCC, SHARPIN expression was low in 52 cases $(68.1 \%)$ and moderate in 25 cases $(31.9 \%)$. Furthermore, the difference in SHARPIN expression levels between BCC and normal skin, SCC and normal skin, and SCC and KA were all significant $(\mathrm{P}<0.05)$ (Fig. 4). However, no significant association was observed between SHARPIN

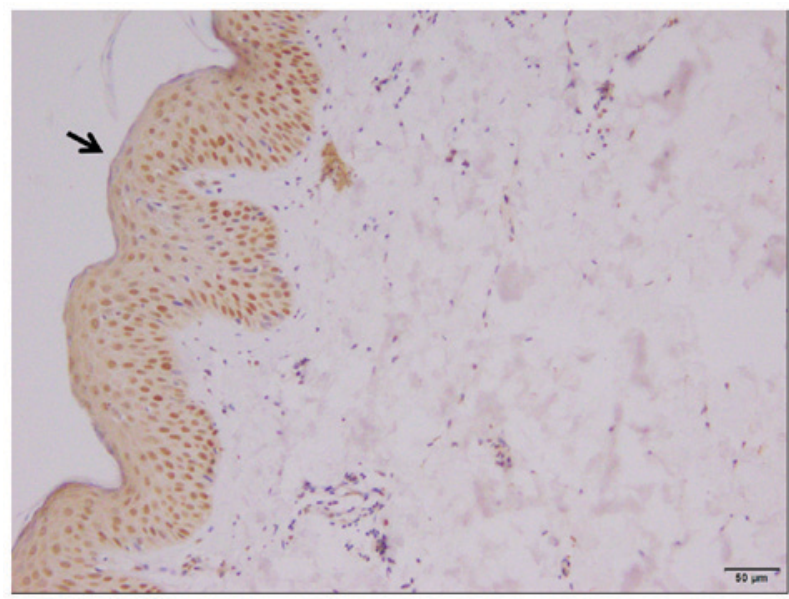

Figure 2. Expression of Src homology 3 and multiple ankyrin repeat domains protein-associated $\mathrm{RH}$ domain-interacting protein in normal skin at magnification, x100. The black arrow indicates the epithelia in normal skin.

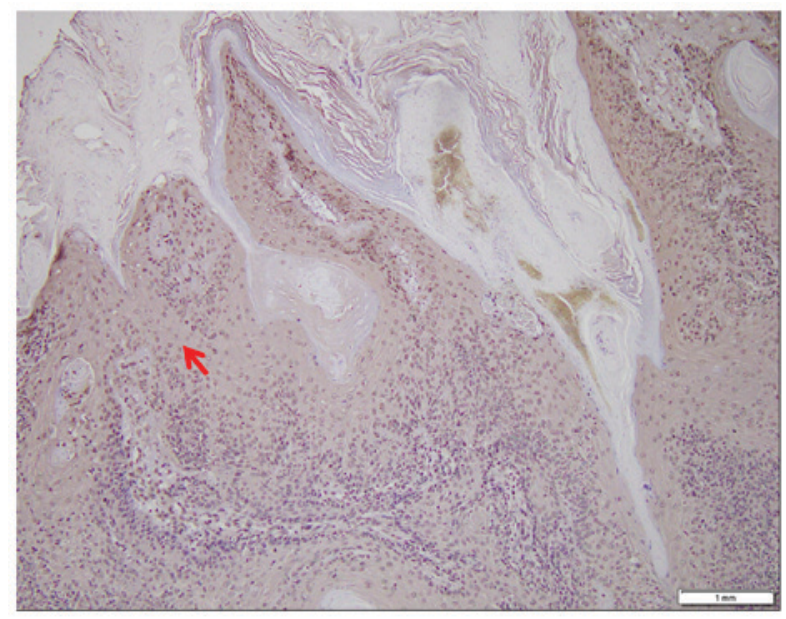

Figure 3. Expression of Src homology 3 and multiple ankyrin repeat domains protein-associated $\mathrm{RH}$ domain-interacting protein in KA at magnification, $\mathrm{x} 200$. The red arrow indicates tumors cells in KA. KA, keratoacanthoma.

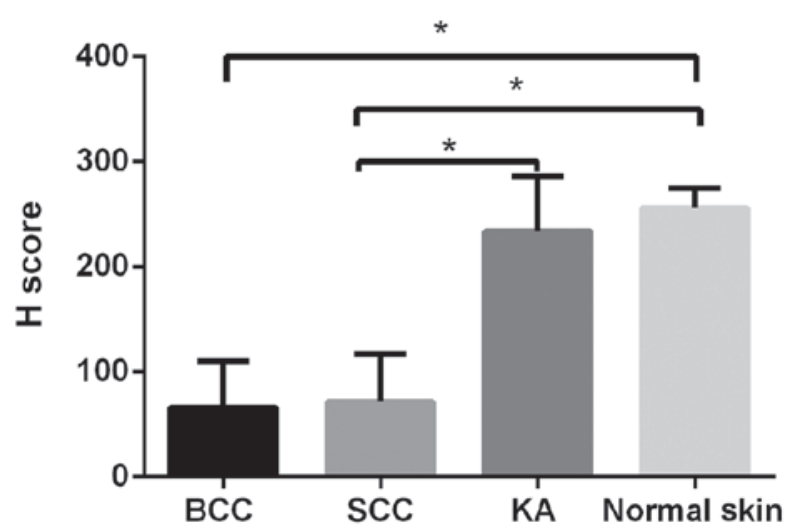

Figure 4. H scores of BCC, SCC, KA and normal skin. Values are mean \pm standard deviation. ${ }^{*} \mathrm{P}<0.05$ using one-way analysis of variance and Tamhane's T2 post hoc test. BCC, basal cell carcinoma; SCC, squamous cell carcinoma; KA, keratoacanthoma.

expression and tumor grading of SCC. Demographics of all the patients and their $\mathrm{H}$ scores are summarized in Tables III-VI. 
Table III. Demographics and H scores of patients with basal cell carcinoma.

\begin{tabular}{|c|c|c|c|c|c|}
\hline ID & Sex & Age, y & Location & Type & H score \\
\hline B01 & M & 74 & Nose & Adenoidal type & 10 \\
\hline B02 & $\mathrm{F}$ & 52 & Right ear & Adenoidal type & 10 \\
\hline B03 & M & 72 & Trunk & Superficial type & 10 \\
\hline B04 & $\mathrm{F}$ & 70 & Right hand & Superficial type & 10 \\
\hline B05 & $\mathrm{M}$ & 68 & Right shoulder & Superficial type & 10 \\
\hline B06 & $\mathrm{M}$ & 62 & Upper lip & Nodular type & 10 \\
\hline B07 & M & 63 & Nose & Adenoidal type & 10 \\
\hline B08 & M & 44 & Lower lip & Sclerosing type & 10 \\
\hline B09 & $\mathrm{F}$ & 82 & Lower lip & Sclerosing type & 10 \\
\hline B10 & $\mathrm{F}$ & 45 & Head & Adenoidal type & 10 \\
\hline B11 & $\mathrm{F}$ & 70 & Nose & Adenoidal type & 15 \\
\hline B12 & $\mathrm{F}$ & 63 & Right hip & Adenoidal type & 20 \\
\hline B13 & $\mathrm{F}$ & 49 & Right thigh & Sclerosing type & 20 \\
\hline B14 & $\mathrm{F}$ & 73 & Left forearm & Superficial type & 20 \\
\hline B15 & $\mathrm{M}$ & 69 & Upper lip & Nodular type & 20 \\
\hline B16 & M & 69 & Nose & Adenoidal type & 20 \\
\hline B17 & M & 65 & Left hand & Sclerosing type & 20 \\
\hline B18 & $\mathrm{M}$ & 67 & Nose & Adenoidal type & 20 \\
\hline B19 & $\mathrm{F}$ & 47 & Nose & Adenoidal type & 20 \\
\hline B20 & M & 65 & Neck & Superficial type & 20 \\
\hline B21 & $\mathrm{F}$ & 73 & Head & Nodular type & 25 \\
\hline B22 & M & 22 & Nose & Nodular type & 30 \\
\hline B23 & $\mathrm{M}$ & 58 & Lower lip & Adenoidal type & 30 \\
\hline B24 & $\mathrm{F}$ & 58 & Nose & Superficial type & 30 \\
\hline B25 & $\mathrm{F}$ & 57 & Left cheek & Adenoidal type & 35 \\
\hline B26 & M & 59 & Upper lip & Adenoidal type & 35 \\
\hline B27 & $\mathrm{F}$ & 68 & Right tempus & Superficial type & 40 \\
\hline B28 & $\mathrm{F}$ & 80 & Upper lip & Pigmented type & 40 \\
\hline B29 & $\mathrm{F}$ & 95 & Back & Nodular type & 40 \\
\hline B30 & $\mathrm{M}$ & 78 & Back & Nodular type & 40 \\
\hline B31 & $\mathrm{F}$ & 65 & Left tempus & Nodular type & 40 \\
\hline B32 & $\mathrm{F}$ & 76 & Back & Pigmented type & 40 \\
\hline B33 & $\mathrm{M}$ & 64 & Left leg & Superficial type & 40 \\
\hline B34 & M & 43 & Head & Sclerosing type & 45 \\
\hline B35 & $\mathrm{F}$ & 41 & Left forehead & Pigmented type & 50 \\
\hline B36 & $\mathrm{F}$ & 68 & Chest & Pigmented type & 50 \\
\hline B37 & $\mathrm{F}$ & 83 & Right hand & Nodular type & 50 \\
\hline B38 & M & 89 & Nose & Superficial type & 50 \\
\hline B39 & $\mathrm{F}$ & 75 & Left hand & Pigmented type & 50 \\
\hline B40 & $\mathrm{F}$ & 75 & Lower lip & Superficial type & 55 \\
\hline B41 & $\mathrm{M}$ & 63 & Nose & Sclerosing type & 55 \\
\hline B42 & $\mathrm{M}$ & 45 & Upper lip & Nodular type & 60 \\
\hline B43 & $\mathrm{F}$ & 64 & Left thigh & Adenoidal type & 60 \\
\hline B44 & M & 50 & Back & Nodular type & 60 \\
\hline B45 & $\mathrm{M}$ & 59 & Lower lip & Nodular type & 60 \\
\hline B46 & $\mathrm{M}$ & 46 & Upper lip & Adenoidal type & 70 \\
\hline B47 & $\mathrm{M}$ & 81 & Head & Nodular type & 70 \\
\hline B48 & $\mathrm{F}$ & 60 & Lower lip & Nodular type & 70 \\
\hline B49 & M & 58 & Left thigh & Adenoidal type & 70 \\
\hline B50 & $\mathrm{F}$ & 43 & Anus & Nodular type & 70 \\
\hline B51 & $\mathrm{F}$ & 78 & Left thigh & Nodular type & 75 \\
\hline
\end{tabular}


Table III. Continued.

\begin{tabular}{|c|c|c|c|c|c|}
\hline ID & Sex & Age, y & Location & Type & H score \\
\hline B52 & $\mathrm{F}$ & 61 & Nose & Nodular type & 80 \\
\hline B53 & $\mathrm{M}$ & 56 & Nose & Nodular type & 80 \\
\hline B54 & $\mathrm{M}$ & 53 & Left thigh & Nodular type & 80 \\
\hline B55 & $\mathrm{F}$ & 45 & Right cheek & Pigmented type & 80 \\
\hline B56 & $\mathrm{F}$ & 29 & Left check & Superficial type & 80 \\
\hline B57 & $\mathrm{F}$ & 44 & Left thigh & Adenoidal type & 80 \\
\hline B58 & $\mathrm{F}$ & 58 & Left thigh & Nodular type & 80 \\
\hline B59 & $\mathrm{F}$ & 73 & Back & Nodular type & 85 \\
\hline B60 & M & 58 & Nose & Superficial type & 90 \\
\hline B61 & $\mathrm{F}$ & 73 & Head & Nodular type & 90 \\
\hline B62 & M & 73 & Left cheek & Sclerosing type & 90 \\
\hline B63 & $\mathrm{F}$ & 57 & Nose & Nodular type & 90 \\
\hline B64 & $\mathrm{F}$ & 34 & Lower lip & Superficial type & 100 \\
\hline B65 & $\mathrm{F}$ & 41 & Nose & Nodular type & 100 \\
\hline B66 & $\mathrm{F}$ & 34 & Lower lip & Superficial type & 100 \\
\hline B67 & $\mathrm{M}$ & 73 & Lower lip & Nodular type & 100 \\
\hline B68 & $\mathrm{M}$ & 82 & Nose & Nodular type & 100 \\
\hline B69 & $\mathrm{M}$ & 63 & Back & Nodular type & 100 \\
\hline B70 & $\mathrm{F}$ & 38 & Upper lip & Superficial type & 105 \\
\hline B71 & $\mathrm{F}$ & 53 & Right tempus & Nodular type & 105 \\
\hline B72 & $\mathrm{F}$ & 64 & Back & Nodular type & 110 \\
\hline B73 & $\mathrm{F}$ & 53 & Lower lip & Nodular type & 120 \\
\hline B74 & $\mathrm{F}$ & 63 & Back & Nodular type & 120 \\
\hline B75 & M & 35 & Upper lip & Superficial type & 120 \\
\hline B76 & $\mathrm{F}$ & 44 & Nose & Superficial type & 130 \\
\hline B77 & $\mathrm{F}$ & 60 & Right tempus & Nodular type & 135 \\
\hline B78 & $\mathrm{F}$ & 70 & Nose & Superficial type & 140 \\
\hline B79 & $\mathrm{M}$ & 37 & Nose & Nodular type & 140 \\
\hline B80 & $\mathrm{F}$ & 36 & Nose & Nodular type & 140 \\
\hline B81 & $\mathrm{F}$ & 64 & Right tempus & Adenoidal type & 150 \\
\hline B82 & $\mathrm{M}$ & 56 & Lower lip & Sclerosing type & 150 \\
\hline B83 & $\mathrm{M}$ & 73 & Back & Superficial type & 160 \\
\hline B84 & $\mathrm{F}$ & 47 & Right hand & Nodular type & 160 \\
\hline B85 & $\mathrm{M}$ & 58 & Lower lip & Nodular type & 190 \\
\hline
\end{tabular}

F, female; M, male.

SHARPIN mutation analysis. A total of 8 exons and exon-intron adjacent sequences of SHARPIN were analyzed using DNA extracts from FFPE blocks of BCC, SCC and KA samples and healthy skin specimens, and DNA extracts from peripheral blood samples of 100 normal controls. Complete descriptions of the mutations detected in BCC and SCC are presented in Table VII. Total mutation rates were $21.8 \%$ in $\mathrm{BCC}$ and $17.0 \%$ in SCC samples. The $\mathrm{C}>\mathrm{T}$ substitutions were $5.5 \%$ in BCC and $6.4 \%$ in SCC. Additionally, no mutations of SHARPIN were detected in DNA extracts from one benign skin tumor, 12 healthy skin tissues and blood samples from 100 normal individuals.

\section{Discussion}

The present study evaluated the expression of SHARPIN protein and analyzed the sequences of SHARPIN in NMSC. To the best of our knowledge, this is the first study to comprehensively investigate the expression and mutations of SHARPIN in a large series of patients with NMSC.

The essential contribution of SHARPIN to the activation of NF- $\kappa \mathrm{B}$ supports the possibility that SHARPIN promotes tumorigenesis, as NF- $\kappa \mathrm{B}$ signaling possesses well-demonstrated tumorigenic properties (12). This is supported by the SHARPIN-mediated suppression of apoptosis in the 
Table IV. Demographics and H scores of patients with squamous cell carcinoma.

\begin{tabular}{|c|c|c|c|c|c|}
\hline ID & Sex & Age, y & Location & Broder grading system & H score \\
\hline S01 & M & 57 & Left tempus & I & 3 \\
\hline S02 & M & 56 & Right tempus & I & 5 \\
\hline S03 & $\mathrm{F}$ & 43 & Right cheek & I & 10 \\
\hline S04 & M & 28 & Nose & II & 10 \\
\hline S05 & $\mathrm{F}$ & 78 & Perioral & II & 10 \\
\hline S06 & M & 72 & Left tempus & I & 10 \\
\hline S07 & M & 79 & Left thigh & II & 20 \\
\hline S08 & $\mathrm{F}$ & 78 & Upper lip & I & 20 \\
\hline S09 & M & 88 & Lower lip & I & 20 \\
\hline S10 & M & 52 & Nose & I & 20 \\
\hline S11 & $\mathrm{F}$ & 59 & Trunk & II & 20 \\
\hline S12 & M & 68 & Right eyebrow & III-IV & 20 \\
\hline S13 & M & 48 & Left eyelid & III & 25 \\
\hline S14 & M & 72 & Left forehead & II & 25 \\
\hline S15 & $\mathrm{F}$ & 42 & Right forearm & II & 25 \\
\hline S16 & M & 65 & Right cheek & I & 30 \\
\hline S17 & $\mathrm{F}$ & 76 & Anus & II & 30 \\
\hline S18 & $\mathrm{F}$ & 30 & Left cheek & II & 30 \\
\hline S19 & M & 61 & Perioral & II & 35 \\
\hline S20 & M & 45 & Left forearm & II & 35 \\
\hline $\mathrm{S} 21$ & M & 63 & Lower lip & IV & 40 \\
\hline S22 & M & 71 & Left cheek & IV & 40 \\
\hline S23 & $\mathrm{F}$ & 73 & Right tempus & I & 40 \\
\hline S24 & $\mathrm{F}$ & 50 & Lower lip & III & 40 \\
\hline S25 & $\mathrm{F}$ & 68 & Lower lip & I & 40 \\
\hline S26 & $\mathrm{F}$ & 30 & Right tempus & I & 40 \\
\hline S27 & M & 41 & Right thigh & I & 40 \\
\hline S28 & $\mathrm{F}$ & 30 & Left eyelid & I & 45 \\
\hline S29 & M & 32 & Left eyelid & I & 50 \\
\hline S30 & $\mathrm{F}$ & 20 & Nose & I & 50 \\
\hline S31 & $\mathrm{F}$ & 81 & Nose & I & 50 \\
\hline S32 & $\mathrm{F}$ & 61 & Left eyelid & I & 50 \\
\hline S33 & $\mathrm{F}$ & 60 & Left cheek & II & 55 \\
\hline S34 & $\mathrm{F}$ & 29 & Nose & I & 55 \\
\hline S35 & M & 86 & Right thigh & II-III & 60 \\
\hline S36 & M & 82 & Nose & III & 60 \\
\hline S37 & $\mathrm{F}$ & 82 & Right cheek & I & 60 \\
\hline S38 & $\mathrm{F}$ & 75 & Right cheek & I & 60 \\
\hline S39 & M & 71 & Left hand & II & 60 \\
\hline S40 & M & 71 & Right tempus & I & 60 \\
\hline S41 & $\mathrm{F}$ & 40 & Right hand & I & 70 \\
\hline S42 & M & 53 & Perioral & I & 70 \\
\hline S43 & $\mathrm{F}$ & 80 & Perioral & I & 70 \\
\hline S44 & M & 71 & Perioral & I & 70 \\
\hline S45 & M & 60 & Left eyelid & II & 80 \\
\hline S46 & $\mathrm{F}$ & 43 & Left cheek & I & 80 \\
\hline S47 & $\mathrm{F}$ & 21 & Left cheek & III & 80 \\
\hline S48 & M & 79 & Lower lip & I & 80 \\
\hline S49 & $\mathrm{F}$ & 80 & Neck & III & 90 \\
\hline S50 & M & 90 & Nose & II-III & 90 \\
\hline S51 & $\mathrm{F}$ & 78 & Left hand & IV & 95 \\
\hline
\end{tabular}


Table IV. Continued.

\begin{tabular}{|c|c|c|c|c|c|}
\hline ID & Sex & Age, $y$ & Location & Broder grading system & H score \\
\hline S52 & M & 64 & Right cheek & II & 95 \\
\hline S53 & M & 57 & Neck & I & 100 \\
\hline S54 & F & 42 & Left hand & I & 100 \\
\hline S55 & M & 81 & Right hand & I & 100 \\
\hline S56 & M & 68 & Left eyelid & I & 100 \\
\hline S57 & M & 53 & Right hand & III & 100 \\
\hline S58 & F & 82 & Left eyelid & III & 100 \\
\hline S59 & F & 71 & Upper lip & I & 100 \\
\hline S60 & M & 32 & Right cheek & I & 110 \\
\hline S61 & F & 82 & Right cheek & I & 110 \\
\hline S62 & F & 75 & Right hand & II & 110 \\
\hline S63 & F & 74 & Upper lip & I & 110 \\
\hline S64 & M & 62 & Left eyelid & II & 110 \\
\hline S65 & M & 47 & Nose & II & 110 \\
\hline S66 & M & 26 & Right hand & III & 120 \\
\hline S67 & F & 57 & Right hand & I & 120 \\
\hline S68 & F & 66 & Left tempus & I-II & 130 \\
\hline S69 & M & 57 & Left thigh & I & 135 \\
\hline S70 & $\mathrm{F}$ & 81 & Left cheek & I & 135 \\
\hline S71 & M & 64 & Trunk & II & 150 \\
\hline S72 & M & 65 & Trunk & I & 150 \\
\hline S73 & M & 64 & Left tempus & I & 160 \\
\hline S74 & M & 60 & Left eyelid & II & 160 \\
\hline S75 & M & 74 & Upper lip & II & 160 \\
\hline S76 & F & 62 & Upper lip & I & 180 \\
\hline S77 & F & 66 & Right cheek & III & 190 \\
\hline
\end{tabular}

F, female; M, male.

keratinocytes and hepatocytes of $c p d m$ mice (18). Additionally, SHARPIN promotes the migration of Chinese hamster ovary cells in vitro and lymphocytes in vivo, and increases the lung metastasis of osteosarcoma in vivo in immunocompromised mice (19). In addition, the upregulation of SHARPIN has been observed in different types of internal solid cancer, including ovarian cancer, renal cell carcinoma, and cervical and prostate cancer (20,21). Furthermore, SHARPIN induces PTEN polyubiquitination independently of the K48 linkage. This process requires the UBL domain, which mediates SHARPIN's association with PTEN and its ability to bind ubiquitin via the NZF motif (28). Rantala et al (16) demonstrated that SHARPIN inactivates integrins in a number of different cell types and affects integrin-dependent cellular functions. Bii et al (22) identified SHARPIN as a metastasis gene in breast cancer using a replication-incompetent gammaretroviral vector, suggesting the potential of SHARPIN as a biomarker for stratifying patients with breast cancer. Additionally, Haris et al (23) identified that SHARPIN was significantly upregulated in U87 glioblastoma cells upon treatment with Aloe-emodin. Collectively, substantial evidence has demonstrated the role of SHARPIN in promoting tumorigenesis. Despite these data, a PubMed search did not identify any studies examining the expression of SHARPIN in NMSC. Therefore, the present study explored the expression of SHARPIN in three types of skin tumors, including the malignant forms BCC and SCC.

Firstly, the expression of SHARPIN was detected via immunohistochemistry. Contrary to the results of examination of internal solid tumors (17), SHARPIN expression was downregulated or absent in the majority of NMSC samples compared with normal skin tissues and KA. KA is commonly diagnosed clinically as it rapidly appears and develops as a raised lesion; however, as a non-pigmented lesion with a central keratin plug, SCC may also exhibit the same appearance. Furthermore, cases of KA with SCC arising from the base have been identified (29). Differential diagnosis between $\mathrm{KA}$ and SCC is challenging due to their similarities and the lack of reliable diagnostic criteria to distinguish them. Therefore, whether KA is a separate benign entity, or a variant of SCC, is controversial. At present, no biomarkers exist to distinguish SCC from KA, and KA lesions are commonly 
Table V. Demographics and $\mathrm{H}$ scores of patients with keratoacanthoma.

\begin{tabular}{lllll}
\hline ID & Sex & Age, y & Location & H score \\
\hline K01 & M & 68 & Nose & 110 \\
K02 & M & 55 & Left cheek & 120 \\
K03 & F & 69 & Trunk & 160 \\
K04 & F & 68 & Right arm & 175 \\
K05 & M & 62 & Upper lip & 180 \\
K06 & F & 69 & Nose & 240 \\
K07 & F & 85 & Trunk & 240 \\
K08 & M & 18 & Forehead & 245 \\
K09 & M & 48 & Upper lip & 245 \\
K10 & F & 69 & Nose & 250 \\
K11 & M & 69 & Right cheek & 250 \\
K12 & M & 40 & Right arm & 250 \\
K13 & F & 55 & Nose & 260 \\
K14 & M & 55 & Nose & 260 \\
K15 & M & 50 & Left arm & 265 \\
K16 & M & 50 & Upper lip & 270 \\
K17 & F & 72 & Forehead & 275 \\
K18 & F & 70 & Left arm & 275 \\
K19 & M & 63 & Trunk & 280 \\
K20 & M & 50 & Forehead & 280 \\
K21 & M & 53 & Right tempus & 280 \\
\hline
\end{tabular}

F, female; M, male.

treated in the same way as SCC. However, SCC has a poorer prognosis than KA and is treated more aggressively; therefore, distinguishing between these two malignancies would be advantageous in order to implement the appropriate treatment, thereby decreasing unnecessary surgeries, the burden on the healthcare system and, importantly, the anxiety of the patients (30). Based on the results of the present study, that SHARPIN is absent or exhibits low expression in SCC but a high expression in KA, we hypothesize that SHARPIN may allow early differentiation and in situ treatment of SCC and KA to avoid metastasis and tissue destruction of SCC and the overtreatment of KA.

At present, the mechanism of how the downregulation of SHARPIN promotes skin tumorigenesis remains to be elucidated. Ikeda et al (11) identified that the absence of SHARPIN in $c p d m$ mice caused dysregulation of $\mathrm{NF}-\kappa \mathrm{B}$ and increased apoptosis and necrosis of mouse embryonic fibroblasts. The data from the present study suggested that the downregulation of SHARPIN in NMSC may impair the function of LUBAC, and subsequently, the activation of $N F-\kappa B$. In the majority of tumors, the aberrant activation of NF- $\kappa \mathrm{B}$ signaling stimulates tumor cell proliferation, invasion and metastasis (31). Counterintuitively, van Hogerlinden et al (32) demonstrated that selective inhibition of Rel/NF- $\kappa \mathrm{B}$ signaling in the skin leads to disturbed epidermal homeostasis and hair follicle development, increased frequency of apoptotic keratinocytes
Table VI. Demographics and H scores of negative control patients.

\begin{tabular}{llcc}
\hline ID & Sex & Age, y & H score \\
\hline N01 & M & 30 & 220 \\
N02 & F & 22 & 260 \\
N03 & F & 57 & 260 \\
N04 & F & 48 & 275 \\
N05 & M & 32 & 280 \\
N06 & F & 50 & 240 \\
N07 & M & 40 & 280 \\
N08 & M & 18 & 245 \\
N09 & M & 39 & 245 \\
N10 & F & 28 & 250 \\
N11 & F & 69 & 270 \\
N12 & M & 55 & 250 \\
\hline
\end{tabular}

F, female; M, male.

and spontaneous development of SCC. Notably, a number of data have challenged the view that apoptotic signaling solely serves to inhibit cancer, arguing instead that apoptosis is responsible for various effects that may be tumor-promoting (33-36). Apoptotic cell death is a cell-autonomous event, but its effects are not; dying cells affect their surrounding environments in various ways, which may include stimulating the proliferation of neighboring cells, affecting intra-tumoral cell competition and exerting paracrine effects on tumor microenvironments. Various data support the hypothesis that apoptosis may promote tumorigenesis through the recruitment and activation of phagocytic macrophages at the tumor sites (37). Taken together, we hypothesized that decreased SHARPIN expression may promote NMSC through the impaired activation of $\mathrm{NF}-\kappa \mathrm{B}$ and increased apoptosis and necrosis of epidermal cells, which may disrupt the homeostasis of the epidermis and lead to tumorigenesis.

Traditional Sanger sequencing has been the gold standard for identifying mutations for a number of years due to its low false-positive rate and high specificity (21). Therefore, in the present study, DNA was extracted from NMSC FFPE blocks and mutations in the exons of SHARPIN were detected. The results indicated that high proportions of BCC and SCC contained mutations of the SHARPIN gene. Mutations in SHARPIN exons were identified in $21.8 \%$ of BCC and $17.0 \%$ of SCC in the present study. The proportions of $\mathrm{C}>\mathrm{T}$ substitutions were 5.5\% in BCC and 6.4\% in SCC samples, which were identified as characteristic of mutations associated with exposure to UV exposure (38). In addition, the mutations were not only located in the UBL domain of SHARPIN but also in the $\mathrm{PH}$ and $\mathrm{NZF}$ domains, thereby potentially affecting other functions of SHARPIN besides the formation of LUBAC. Furthermore, SHARPIN has been indicated to inactivate integrins in a number of cell types and affect integrin-dependent cellular functions independent of LUBAC (16). Approximately one-half of the cellular SHARPIN is not associated with the 
Table VII. Distribution of Src homology 3 and multiple ankyrin repeat domains protein-associated RH domain-interacting protein gene mutations in patients with BCC and SCC.

\begin{tabular}{|c|c|c|c|c|c|}
\hline Tumor type & Exon & Mutation & Modified protein & Frequency & Domain \\
\hline \multirow[t]{10}{*}{$\mathrm{BCC}$} & E1 & c. $10 \mathrm{C}>\mathrm{T}$ & p.Pro4Leu & $1 / 55$ & - \\
\hline & - & c. $68 \mathrm{C}>\mathrm{T}$ & p.Ala23 Val & $1 / 55$ & - \\
\hline & - & c. $146 \mathrm{~A}>\mathrm{G}$ & p.Asp49Gly & $1 / 55$ & - \\
\hline & E2 & c. $329 \mathrm{~T}>\mathrm{C}$ & p.Gln110Arg & $1 / 55$ & PH \\
\hline & E5 & c. $733 \mathrm{C}>\mathrm{A}$ & p.His245Thr & $1 / 55$ & UBL \\
\hline & E7 & c. $937 \mathrm{C}>\mathrm{T}$ & p.Pro313Ser & $1 / 55$ & - \\
\hline & - & c. $944 \mathrm{~A}>\mathrm{G}$ & p.His315Arg & $1 / 55$ & - \\
\hline & - & c.992 T>C & p.Leu332Ser & $3 / 55$ & - \\
\hline & E8 & c. $1109 \mathrm{~T}>\mathrm{C}$ & p.Met370Thr & $1 / 55$ & $\mathrm{NZF}$ \\
\hline & - & c. $1137 \mathrm{G}>\mathrm{A}$ & p.Trp379Gln & $1 / 55$ & - \\
\hline \multirow[t]{8}{*}{$\mathrm{SCC}$} & E1 & c. $.53 \mathrm{C}>\mathrm{A}$ & p.Ala18Asp & $1 / 47$ & - \\
\hline & E2 & c. $214 \mathrm{~T}>\mathrm{C}$ & p.Trp72Arg & $1 / 47$ & PH \\
\hline & E3 & c. $421 \mathrm{C}>\mathrm{T}$ & p.Pro141Ser & $1 / 47$ & - \\
\hline & - & c. $466 \mathrm{C}>\mathrm{T}$ & p.Pro156Ser & $1 / 47$ & - \\
\hline & - & c. $469 \mathrm{C}>\mathrm{T}$ & p.Pro157Ser & $1 / 47$ & - \\
\hline & - & c. $478 \mathrm{G}>\mathrm{A}$ & p.Ala160Thr & $1 / 47$ & - \\
\hline & E5 & c.709 T>C & p.Ser237Pro & $1 / 47$ & - \\
\hline & E8 & c. $1007 \mathrm{G}>\mathrm{T}$ & p.Gly336Val & $1 / 47$ & - \\
\hline
\end{tabular}

BCC, basal cell carcinoma; SCC, squamous cell carcinoma; PH, pleckstrin homology domain; UBL, ubiquitin-like; NZF, Npl4 zinc finger.

LUBAC complex (28). Therefore, the present study concluded that SHARPIN is a multifunctional molecule and may promote the pathogenesis of NMSC through different mechanisms.

Overall, the present study contributes to a growing body of evidence supporting the importance of SHARPIN in NMSC. The results suggest an association between NMSC and low to absent SHARPIN expression and SHARPIN mutations.

It was identified that SHARPIN protein expression was absent in cancer nests and significantly decreased in precancerous lesions of SCC and BCC, but was high in normal skin or in KA. The total mutation rates of SHARPIN were $21.8 \%$ in BCC and $17.0 \%$ in SCC. These data indicated that SHARPIN may serve a tumor-suppressing role and act as a promising diagnostic biomarker in NMSC.

\section{Acknowledgements}

Not applicable.

\section{Funding}

The present study was supported by the National Natural Science Foundation of China (grant no., 81371724) to Dr Yanhua Liang.

\section{Availability of data and materials}

The datasets used and/or analyzed during the present study are available from the corresponding authors on reasonable request.

\section{Authors' contributions}

YL designed and supervised the study. YZ performed the histological examination of the samples and prepared the draft. YY performed the DNA extraction, polymerase chain reaction and sequencing. JW conducted data analysis and interpreted the data.

\section{Ethics approval and consent to participate}

Blood specimens of 100 normal individuals and skin tissues from 12 healthy volunteers who received cosmetic surgeries, and formalin-fixed paraffin-embedded (FFPE) samples from the Department of Dermatology of Shenzhen Hospital in Southern Medical University (Shenzhen, China), were obtained according to a protocol approved by the Southern Medical University Shenzhen Hospital Subject Review Board (2016-016). All samples were fixed for $24 \mathrm{~h}$ in $10 \%$ formalin solution at room temperature. The thickness of the sections was $4 \mu \mathrm{m}$. Informed consent was obtained from all participants.

\section{Patient consent for publication}

Consent was gained from the participants for the publication of their data.

\section{Competing interests}

The authors declare that they have no competing interests. 


\section{References}

1. Rodust PM, Stockfleth E, Ulrich C, Leverkus M and Eberle J: UV-induced squamous cell carcinoma-a role for antiapoptotic signalling pathways. Br J Dermatol 161 (Suppl 3): S107-S115, 2009.

2. Molho-Pessach V and Lotem M: Ultraviolet radiation and cutaneous carcinogenesis. Curr Probl Dermatol 35: 14-27, 2007.

3. de Villiers EM, Ruhland A and Sekarić P: Human papillomaviruses in non-melanoma skin cancer. Semin Cancer Biol 9 413-422, 1999.

4. McNaughton SA, Marks GC and Green AC: Role of dietary factors in the development of basal cell cancer and squamous cell cancer of the skin. Cancer Epidemiol Biomarkers Prev 14: 1596-1607, 2005.

5. Ramsay HM, Fryer AA, Reece S, Smith AG and Harden PN: Clinical risk factors associated with nonmelanoma skin cancer in renal transplant recipients. Am J Kidney Dis 36: 167-176, 2000.

6. Giglia-Mari G and Sarasin A: TP53 mutations in human skin cancers. Hum Mutat 21: 217-228, 2003.

7. Madan V, Lear JT and Szeimies RM: Non-melanoma skin cancer. Lancet 375: 673-685, 2010.

8. Eisemann N, Jansen L, Castro FA, Chen T, Eberle A, Nennecke A, Zeissig SR, Brenner H and Katalinic A; GEKID Cancer Survival Working Group: Survival with nonmelanoma skin cancer in Germany. Br J Dermatol 174: 778-785, 2016.

9. Stieglitz B, Haire LF, Dikic I and Rittinger K: Structural analysis of SHARPIN, a subunit of a large multi-protein E3 ubiquitin ligase, reveals a novel dimerization function for the pleckstrin homology superfold. J Biol Chem 287: 20823-20829, 2012

10. Seymour RE, Hasham MG, Cox GA, Shultz LD, Hogenesch H, Roopenian DC and Sundberg JP: Spontaneous mutations in the mouse Sharpin gene result in multiorgan inflammation, immune system dysregulation and dermatitis. Genes Immun 8: 416-421, 2007.

11. Ikeda F, Deribe YL, Skånland SS, Stieglitz B, Grabbe C, Franz-Wachtel M, van Wijk SJ, Goswami P, Nagy V, Terzic J, et al: SHARPIN forms a linear ubiquitin ligase complex regulating NF- $\kappa$ B activity and apoptosis. Nature 471: 637-641, 2011.

12. Tokunaga F, Nakagawa T, Nakahara M, Saeki Y, Taniguchi M, Sakata S, Tanaka K, Nakano H and Iwai K: SHARPIN is a component of the NF-kB-activating linear ubiquitin chain assembly complex. Nature 471: 633-636, 2011.

13. Haas AL: Linear polyubiquitylation: The missing link in NF-kappaB signalling. Nat Cell Biol 11: 116-118, 2009.

14. Tokunaga F, Sakata S, Saeki Y, Satomi Y, Kirisako T, Kamei K, Nakagawa T, Kato M, Murata S, Yamaoka S, et al: Involvement of linear polyubiquitylation of NEMO in NF-kappaB activation. Nat Cell Biol 11: 123-132, 2009.

15. Wang Z, Potter CS, Sundberg JP and Hogenesch H: SHARPIN is a key regulator of immune and inflammatory responses. J Cell Mol Med 16: 2271-2279, 2012.

16. Rantala JK, Pouwels J, Pellinen T, Veltel S, Laasola P, Mattila E, Potter CS, Duffy T, Sundberg JP, Kallioniemi O, et al: SHARPIN is an endogenous inhibitor of $\beta 1$-integrin activation. Nat Cell Biol 13: 1315-1324, 2011.

17. Jung J, Kim JM, Park B, Cheon Y, Lee B, Choo SH, Koh SS and Lee S: Newly identified tumor-associated role of human Sharpin. Mol Cell Biochem 340: 161-167, 2010.

18. Sieber S, Lange N, Kollmorgen G, Erhardt A, Quaas A, Gontarewicz A, Sass G, Tiegs G and Kreienkamp HJ: Sharpin contributes to TNF $\alpha$ dependent $\mathrm{NF} \kappa \mathrm{B}$ activation and anti-apoptotic signalling in hepatocytes. PLoS One 7: e29993, 2012.

19. De Melo J and Tang D: Elevation of SIPL1 (SHARPIN) increases breast cancer risk. PLoS One 10: e0127546, 2015.

20. Zhang Y, Huang H, Zhou H, Du T, Zeng L, Cao Y, Chen J, Lai Y, Li J, Wang G, et al: Activation of nuclear factor $\kappa \mathrm{B}$ pathway and downstream targets survivin and livin by SHARPIN contributes to the progression and metastasis of prostate cancer. Cancer 120 : 3208-3218, 2014.
21. Li Q, Li M, Ma L, Li W, Wu X, Richards J, Fu G, Xu W, Bythwood T, Li X, et al: A method to evaluate genome-wide methylation in archival formalin-fixed, paraffin-embedded ovarian epithelial cells. PLoS One 9: e104481, 2014.

22. Bii VM, Rae DT and Trobridge GD: A novel gammaretroviral shuttle vector insertional mutagenesis screen identifies SHARPIN as a breast cancer metastasis gene and prognostic biomarker. Oncotarget 6: 39507-39520, 2015.

23. Haris K, Ismail S, Idris Z, Abdullah JM and Yusoff AA: Expression profile of genes modulated by Aloe emodin in human U87 glioblastoma cells. Asian Pac J Cancer Prev 15: 4499-4505, 2014.

24. Ghaheri M, Kahrizi D, Yari K, Babaie A, Suthar RS and Kazemi E: A comparative evaluation of four DNA extraction protocols from whole blood sample. Cell Mol Biol 62: 120-124, 2016.

25. Bollag G, Hirth P, Tsai J, Zhang J, Ibrahim PN, Cho H, Spevak W, Zhang C, Zhang Y, Habets G, et al: Clinical efficacy of a RAF inhibitor needs broad target blockade in $B R A F$-mutant melanoma. Nature 467: 596-599, 2010.

26. Kallini JR, Hamed N and Khachemoune A: Squamous cell carcinoma of the skin: Epidemiology, classification, management, and novel trends. Int J Dermatol 54: 130-140, 2015.

27. Paolino G, Donati M, Didona D, Mercuri SR and Cantisani C: Histology of non-melanoma skin cancers: An update. Biomedicines 5: pii: E71, 2017.

28. De Melo J, Lin X, He L, Wei F, Major P and Tang D: SIPL1-facilitated PTEN ubiquitination contributes to its association with PTEN. Cell Signal 26: 2749-2756, 2014.

29. Weedon DD, Malo J, Brooks D and Williamson R: Squamous cell carcinoma arising in keratoacanthoma: A neglected phenomenon in the elderly. Am J Dermatopathol 32: 423-426, 2010.

30. Vasiljević N, Andersson K, Bjelkenkrantz K, Kjellström C, Månsson H, Nilsson E, Landberg G, Dillner J and Forslund O: The Bcl-xL inhibitor of apoptosis is preferentially expressed in cutaneous squamous cell carcinoma compared with that in keratoacanthoma. Int J Cancer 124: 2361-2366, 2009.

31. Karin $M$ and Greten FR: NF-kappaB: Linking inflammation and immunity to cancer development and progression. Nat Rev Immunol 5: 749-759, 2005

32. van Hogerlinden M, Rozell BL, Ahrlund-Richter L and Toftgård R: Squamous cell carcinomas and increased apoptosis in skin with inhibited Rel/nuclear factor-kappaB signaling. Cancer Res 59: 3299-3303, 1999.

33. Michalak EM, Vandenberg CJ, Delbridge AR, Wu L, Scott CL, Adams JM and Strasser A: Apoptosis-promoted tumorigenesis: Gamma-irradiation-induced thymic lymphomagenesis requires Puma-driven leukocyte death. Genes Dev 24: 1608-1613, 2010.

34. Li F, Huang Q, Chen J, Peng Y, Roop DR, Bedford JS and Li CY: Apoptotic cells activate the 'phoenix rising' pathway to promote wound healing and tissue regeneration. Sci Signal 3: ra13, 2010.

35. Huang Q, Li F, Liu X, Li W, Shi W, Liu FF, O'Sullivan B, He Z, Peng Y, Tan AC, et al: Caspase 3-mediated stimulation of tumor cell repopulation during cancer radiotherapy. Nat Med 17: 860-866, 2011

36. Qiu W, Wang X, Leibowitz B, Yang W, Zhang L and Yu J: PUMA-mediated apoptosis drives chemical hepatocarcinogenesis in mice. Hepatology 54: 1249-1258, 2011.

37. Ichim G and Tait SW: A fate worse than death: Apoptosis as an oncogenic process. Nat Rev Cancer 16: 539-548, 2016.

38. Scott GA, Laughlin TS and Rothberg PG: Mutations of the TERT promoter are common in basal cell carcinoma and squamous cell carcinoma. Mod Pathol 27: 516-523, 2014.

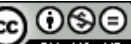

This work is licensed under a Creative Commons Attribution-NonCommercial-NoDerivatives 4.0 International (CC BY-NC-ND 4.0) License. 